\title{
Focusing on outcomes: Making the most of COPD interventions
}

\author{
Noreen M Clark' \\ Julia A Dodge' \\ Martyn R Partridge ${ }^{2}$ \\ Fernando J Martinez ${ }^{3}$ \\ 'Center for Managing Chronic \\ Disease, University of Michigan, Ann \\ Arbor, MI, USA; ${ }^{2}$ mperial College of \\ Science, Technology and Medicine, \\ London, England, UK; ${ }^{3}$ Department \\ of Internal Medicine, University of \\ Michigan Health System, Ann Arbor, \\ Michigan, USA
}

\begin{abstract}
A number of excellent intervention studies related to clinical and psychosocial aspects of chronic obstructive pulmonary disease (COPD) have been undertaken in the recent past. A range of outcomes have been examined including pulmonary function, health care use, quality of life, anxiety and depression, ambulation, exercise capacity, and self-efficacy. The purpose of this narrative review was to a) consider clinical, psychosocial, and educational interventions for people living with COPD in light of the health related outcomes that they have produced, b) identify the type of interventions most associated with outcomes, c) examine work related to COPD interventions as it has evolved regarding theory and models compared to work in asthma, and d) explore implications for future COPD research. Studies reviewed comprised large scale comprehensive reviews including randomized clinical trials and metaanalysis as these forms of investigation engender the greatest confidence in clinicians and health care researchers. Extant research suggests that the most significant improvements in COPD health care utilization have been realized from interventions specifically designed to enhance disease management by patients. A range of interventions have produced modest changes in quality of life. Evidence of impact for other outcomes and for a particular type of intervention is not strong. Research in other chronic diseases, particularly asthma, suggests that interventions grounded in learning theory and models of behavior change can consistently produce desired results for patients and clinicians. Use of a model of self-regulation may enhance COPD interventions. Although the extent to which COPD efforts can benefit from the experience in other conditions is a question, more outcome focused intervention studies using more robust theoretical approaches may enhance COPD results, especially regarding health care use and quality of life.
\end{abstract}

Keywords: COPD, disease management, self-regulation

\section{Introduction}

The trajectory of chronic obstructive pulmonary disease (COPD) can be daunting

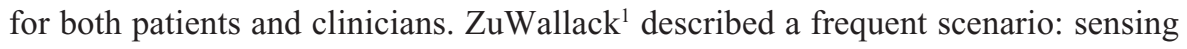
breathlessness on exertion patients settle into a sedentary lifestyle that de-conditions their bodies and further aggravates breathlessness and results in further downward adjustments of physical activity. Such decline is often accompanied by significant limitations on functioning and increased anxiety and depression. ${ }^{2}$ Indeed, estimates of depression in the COPD population are around $50 \%{ }^{3}$ or for severe COPD approximately 2.5 times greater than in an age-matched control population. ${ }^{4}$ The natural course of the disease produces decline in forced expiratory volume in one second $\left(\mathrm{FEV}_{1}\right)$ accelerating disability and death. Tashkin ${ }^{5}$ noted that although lung function is important for diagnosis and classification of severity of COPD, patients and clinicians are very interested in controlling symptoms and maintaining the ability of the patient to function day to day. Modifying these latter outcomes may or may not have an affect on the natural course of the disease ${ }^{5}$ and large scale studies (TORCH, UPLIFT) have been undertaken to address this question. ${ }^{6}$ Several authors have 
posited that clinical measures such as spirometry are much less important to patients than clinicians. Patients studied appeared to place significantly more value on symptom control, functioning and quality of life including less depression and anxiety ${ }^{7-9}$ and they feared exacerbations, hospitalization, and dependency. ${ }^{10}$

Studies to date examining the efficacy of clinical and psychosocial interventions for COPD represent a wide range of efforts (see Table 2) including interventions of varying types and with various emphases to enhance the capacity of individuals to manage their condition on their own with guidance from clinicians. Other types of interventions include community-based management, progressive resistance exercises, pulmonary rehabilitation with and without education, inspiratory muscle training, psychotherapy and psychiatry, psycho-educational interventions, walking and exercise programs. Although many of these efforts are laudable, as a group they reflect a lack of consensus in the field more generally concerning how patients with COPD can best be helped and where emphasis ought to be placed.

Reviews of studies in other diseases, for example asthma $^{11}$ have shown that different types of interventions produce different outcomes. It is rare to find an intervention that achieves the full range of results one might wish for a patient with the condition. Further, studies in asthma over a long period of time suggest that bench marks of success have emerged. So many asthma interventions, most particularly those designed to enhance disease management by the patient, have demonstrated reductions in symptoms and health care use, that an intervention that does not produce at least one of these outcomes can be thought to be wanting. Further, asthma studies and those in other conditions (for example heart disease) also have shown that interventions are often effective with subgroups of patients (eg, ones with more severe disease) exhibiting stronger outcomes for these groups of patients than the entire sample of more heterogeneous participants. ${ }^{12}$ Studies in medicine and pharmacy regarding variation in response ${ }^{13}$ underscore the idea that one size does not fit all patients, that is, what elicits a response from some fails with others. Cost is also an acknowledged concern in management of most long term diseases. When the same desired outcomes are achieved by two interventions of different resource intensity, the less expensive one will be deemed more favorable.

Data are available from studies in COPD regarding a range of outcomes: pulmonary function, health care use, quality of life, anxiety, depression, ambulation, exercise capacity, self-efficacy (the last of these likely not being a sufficient end point in itself but having been associated with other outcomes such as ambulation and symptoms). ${ }^{14}$ The purpose of this narrative review was to a) consider clinical, psychosocial, and educational interventions for people living with COPD in light of the health related outcomes that they have produced, b) identify the type of interventions most associated with outcomes, c) examine work related to COPD interventions as it has evolved regarding theory and models compared to work in asthma, and d) explore implications for future COPD research. Studies reviewed comprised large scale comprehensive reviews including randomized clinical trials and meta-analysis as these forms of investigation engender the greatest confidence in clinicians and health care researchers.

\section{Reviews and studies in COPD: clinical, psychosocial, and educational intervention research}

In the recent past, there have been at least ten comprehensive reviews of COPD clinical, psychosocial and educational interventions involving more than 300 articles. These reviews comprise thoughtful and, generally, methodologically sound treatises on the state of evaluation research (see Table 1 for reviews organized by primary outcome). In addition to comprehensive reviews, recent individual studies have also examined various clinical, psychosocial and educational strategies designed to generate benefits for patients with COPD. Table 2 presents these, also organized by the primary outcome. For purposes of our discussion, it seems helpful to consider findings of reviews and individual randomized controlled studies in light of the outcomes assessed.

\section{Pulmonary function}

A review by Devine and Pearcy ${ }^{15}$ showed that pulmonary rehabilitation interventions including an educational component improved pulmonary function tests, eg, $\mathrm{FEV}_{1}$, for patients with COPD. O'Brien and colleagues ${ }^{16}$ reviewed studies of inspiratory muscle training interventions and found that they resulted in increased muscle strength for COPD patients. A study by Watson and colleagues ${ }^{17}$ found that patients taking part in an intervention to enhance their disease management skills had changes in behavior but no differences compared to controls on any parameter of lung function. Sassi-Dambron and colleagues ${ }^{18}$ noted that 
instruction and practice in techniques of progressive muscle relaxation and breathing retraining produced positive results on the transition dyspnea index.

\section{Health care utilization}

This outcome has received the most attention in COPD studies. In their review (see Table 1), Adams and colleagues ${ }^{19}$ found that interventions including two or more components of the Chronic Care Model (a comprehensive model describing numerous dimensions of health care systems thought to be influential in patient outcomes) produced positive changes in health care utilization among COPD patients. Bourbeau and colleagues ${ }^{20}$ reviewed interventions with diverse theoretical bases and areas of emphasis that aimed to enhance disease management by patients. They found that these interventions were likely to improve COPD health care use. A review by Effing and colleagues ${ }^{21}$ also found that this type of intervention was associated with fewer hospital admissions for COPD patients.

At least eight groups of investigators confirmed positive health care use outcomes in recent studies of COPD interventions (see Table 2). Boxall and colleagues ${ }^{22}$ found that a walking intervention for patients resulted in shorter length of stay for a subsequent hospitalization for COPD. Gallefoss ${ }^{23}$ found an intervention providing COPD information delivered by health care professionals resulted in reduced need for GP visits. Rea and colleagues ${ }^{24}$ showed that patients assigned to pulmonary rehabilitation had reduced number of annual days in the hospital subsequent to their participation. In a study of the efficacy of a community-based disease management intervention for people with COPD, Hernande $\mathrm{z}^{25}$ found that specialized care with a nurse coordinator led to lower rates of emergency department visits. Pushparajah and colleagues ${ }^{26}$ found that patients with previous hospital admissions were more likely to have a shorter length of stay in a subsequent hospitalization after participating in the intervention.

Sridhar and colleagues ${ }^{27}$ found that a nurse-led intervention of pulmonary rehabilitation, enhancement of management skills of patients, and COPD action plans led to reduced need for primary care consultations and a reduction in deaths but had no effect on hospital readmissions. Bourbeau and colleagues $^{28}$ found that an intervention to improve management by patients (Living Well with COPD) resulted in declines in health care use and the same group of investigators reported that patients assigned to a similar intervention reduced by almost $40 \%$ hospitalizations for COPD. Such magnitude of benefit has not so far been replicated by others. Griffiths and colleagues ${ }^{29}$ showed that comprehensive pulmonary rehabilitation, including enhancement of patient management skills, reduced length of stay in a subsequent hospitalization. Gadoury and colleagues ${ }^{30}$ found patients assigned to the Living Well intervention had an overall reduction in hospitalizations and emergency visits.

\section{Quality of life}

Niesink and colleagues ${ }^{31}$ reviewed (see Table 1 ) a variety of interventions, including those to enhance disease management by patients, and concluded that they were in general associated with slight improvements in quality of life. Gallefoss and colleagues ${ }^{23}$ (see Table 2) studied a brief informational session given by health care providers and found improvements in quality of life up to 12 months post-intervention. Hermiz and colleagues ${ }^{32}$ followed patients assigned to home visits by a nurse and showed that some elements of quality of life were improved for the treatment group. Maa and colleagues ${ }^{33}$ looked at acupuncture and acupressure and found that when these were supplements to standard care, quality of life improvements were observed.

\section{Anxiety and depression}

Three recent reviews (see Table 1) assessed interventions to reduce anxiety. Brenes ${ }^{34}$ found that psychotherapy, psychopharmacology, and pulmonary rehabilitation including one or both of these forms of treatment reduced anxiety in COPD patients. Rose and colleagues ${ }^{35}$ examined diverse interventions and concluded that psychology-based interventions were the least effective among strategies to reduce anxiety while Coventry and $\mathrm{Hind}^{36}$ determined that reductions in mild to moderate levels of anxiety were achieved in patients with moderate to severe COPD from such interventions. As seen in Table 2, in a study of individually-provided information, home-based walking or exercise self-monitoring, Nguyen and Carrieri-Kohlman ${ }^{37}$ found that all three modes reduced depressed mood in patients with moderate to severe COPD.

Emery and colleagues ${ }^{38}$ found that in moderate to severe COPD patients comprehensive pulmonary rehabilitation reduced anxiety. In the study by Griffiths and colleagues ${ }^{29}$ of comprehensive pulmonary rehabilitation including enhancement of patients' disease management skills, anxiety levels of COPD patients diminished but there was no difference between groups by the three month time period. White and colleagues ${ }^{39}$ compared pulmonary rehabilitation with brief advice giving and found no difference in anxiety and

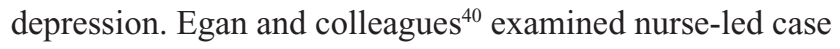
management and found less anxiety at one month but results were not sustained thereafter. 


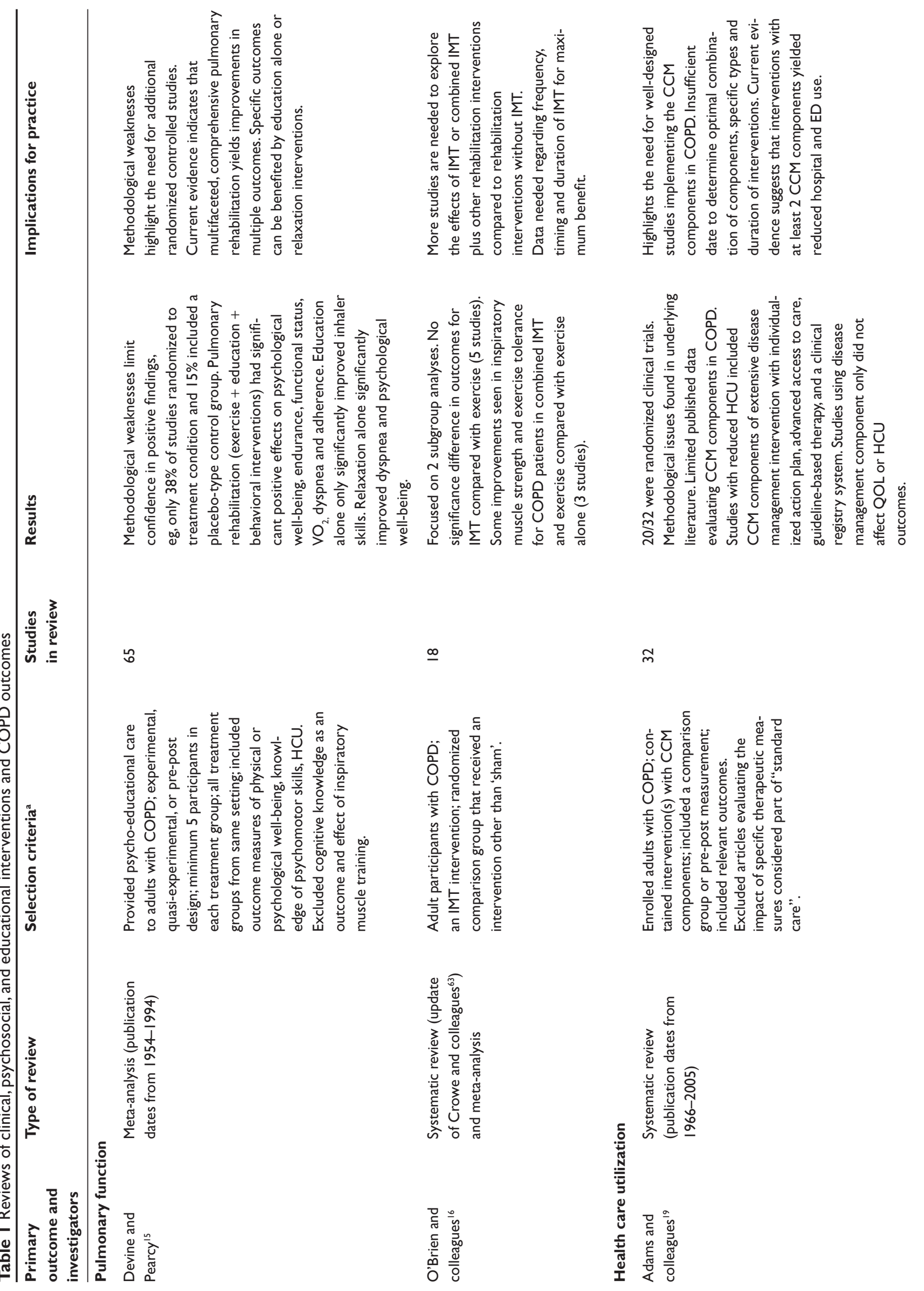



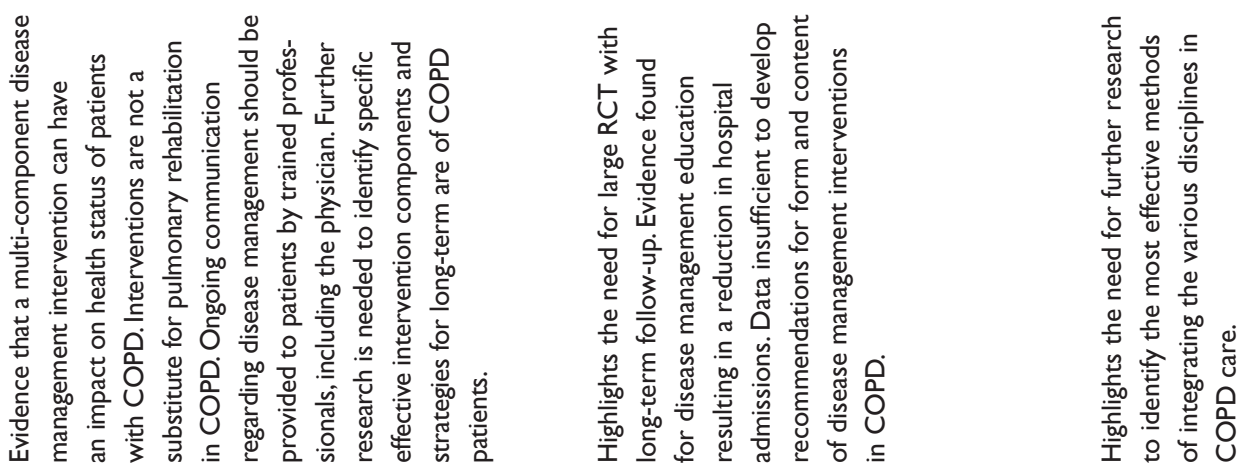

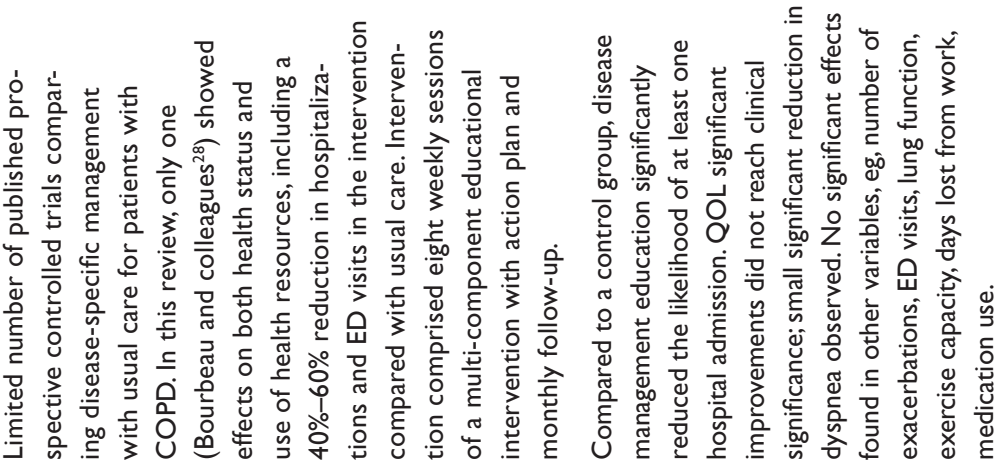

으

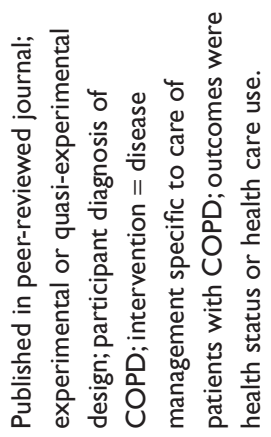

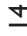

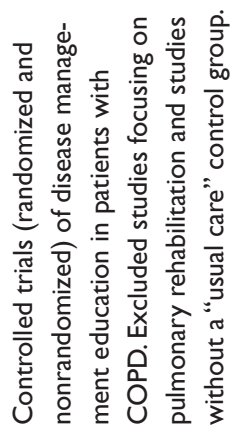

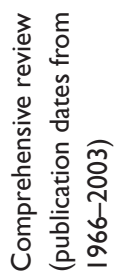

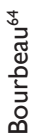

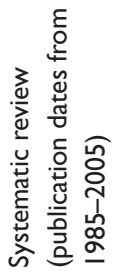

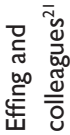

으

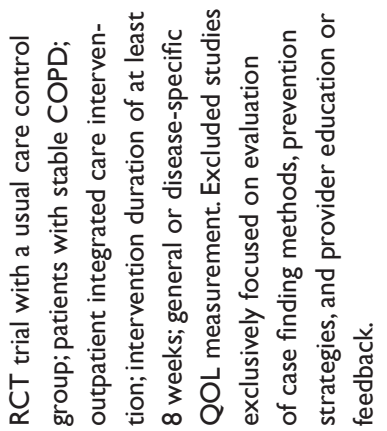

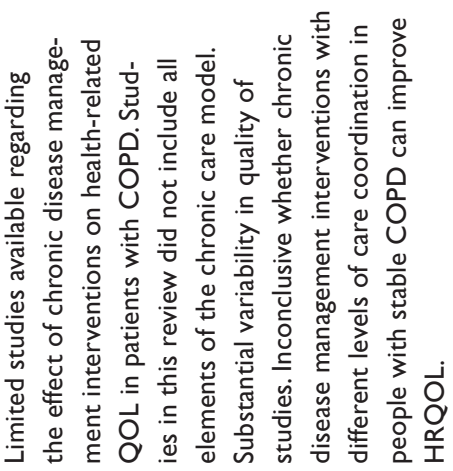
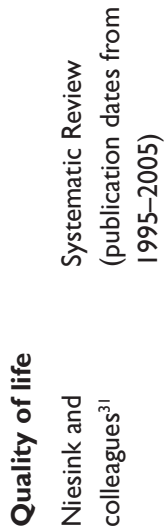


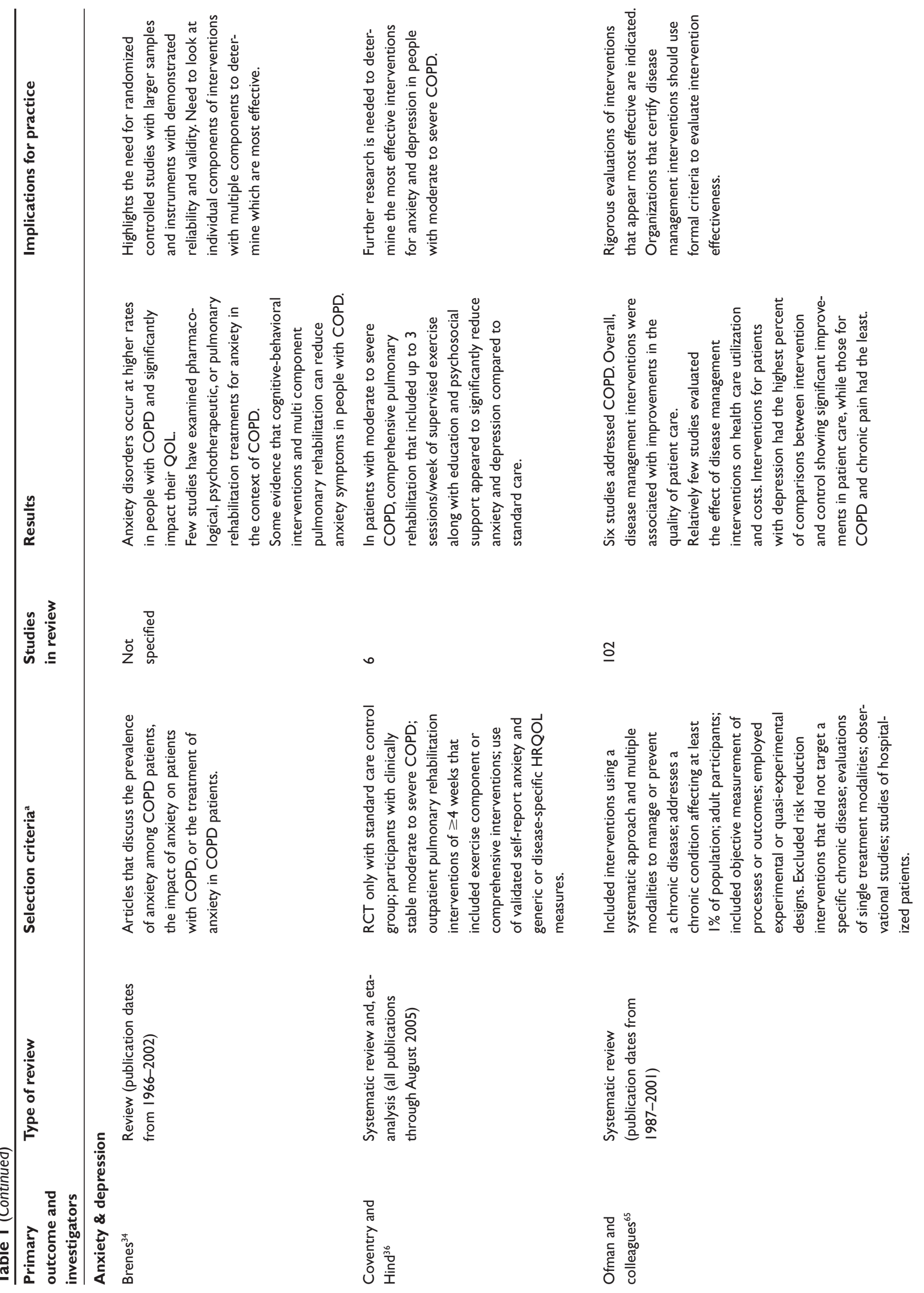



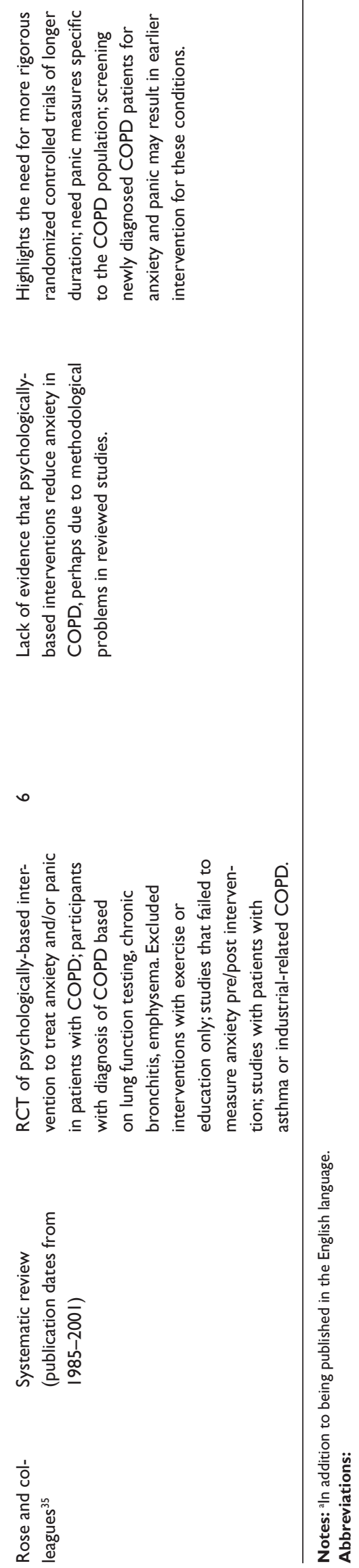

\section{Ambulation and exercise capacity}

Five groups of investigators assessed the efficacy of interventions to achieve these outcomes (see Table 2). Cockcroft and colleagues ${ }^{41}$ found an exercise intervention improved ambulation while Behnke and colleagues ${ }^{42}$ found a home walking intervention improved walking distance and maintenance for six months. Foy and colleagues ${ }^{43}$ found that long-term versus short-term exercise therapy produced greater ambulation scores for men but not women. Ries and colleagues ${ }^{44}$ found patients with moderate to severe COPD who took part in a comprehensive intervention including of breathing exercises, postural drainage education and psychosocial support produced greater increases in exercise that diminished after one year. Guell and colleagues ${ }^{45}$ found that comprehensive pulmonary rehabilitation resulted in greater functional exercise capacity.

\section{Self-efficacy}

Self-efficacy is generally defined as the level of confidence one feels to perform a given task. ${ }^{46}$ Self-efficacy has been linked to other outcomes, although it is a questionable goal if it is the only result of an intervention. Nonetheless, selfefficacy has been studied independently in COPD. Davis and colleagues ${ }^{14}$ found that after dyspnea education and home walking coupled with an exercise intervention there were no differences in self-efficacy between the treatment and control groups. Scherer and colleagues ${ }^{47}$ showed that subsequent to a pulmonary rehabilitation intervention, selfefficacy scores of participants improved and were maintained up to six months.

\section{In summary}

These reviews and studies suggest that there have been improvements realized from COPD interventions. Using the criteria of number of studies conducted and number illustrating positive, statistically significant results, the most consistent findings appear to be for interventions to enhance disease management skills of patients as they produce health care utilization outcomes. Although not definitive, evidence seems to be somewhat more robust for the ability of these interventions than for other types, to realize service use reductions. Some improvements in quality of life have been noted from a variety of interventions but evidence of success is not strong. For the collective of intervention studies conducted to date questions of significance can be raised. For example, how clinically important are the observed reductions related to anxiety and depression? How important over time are initial results related to pulmonary function? Issues of 


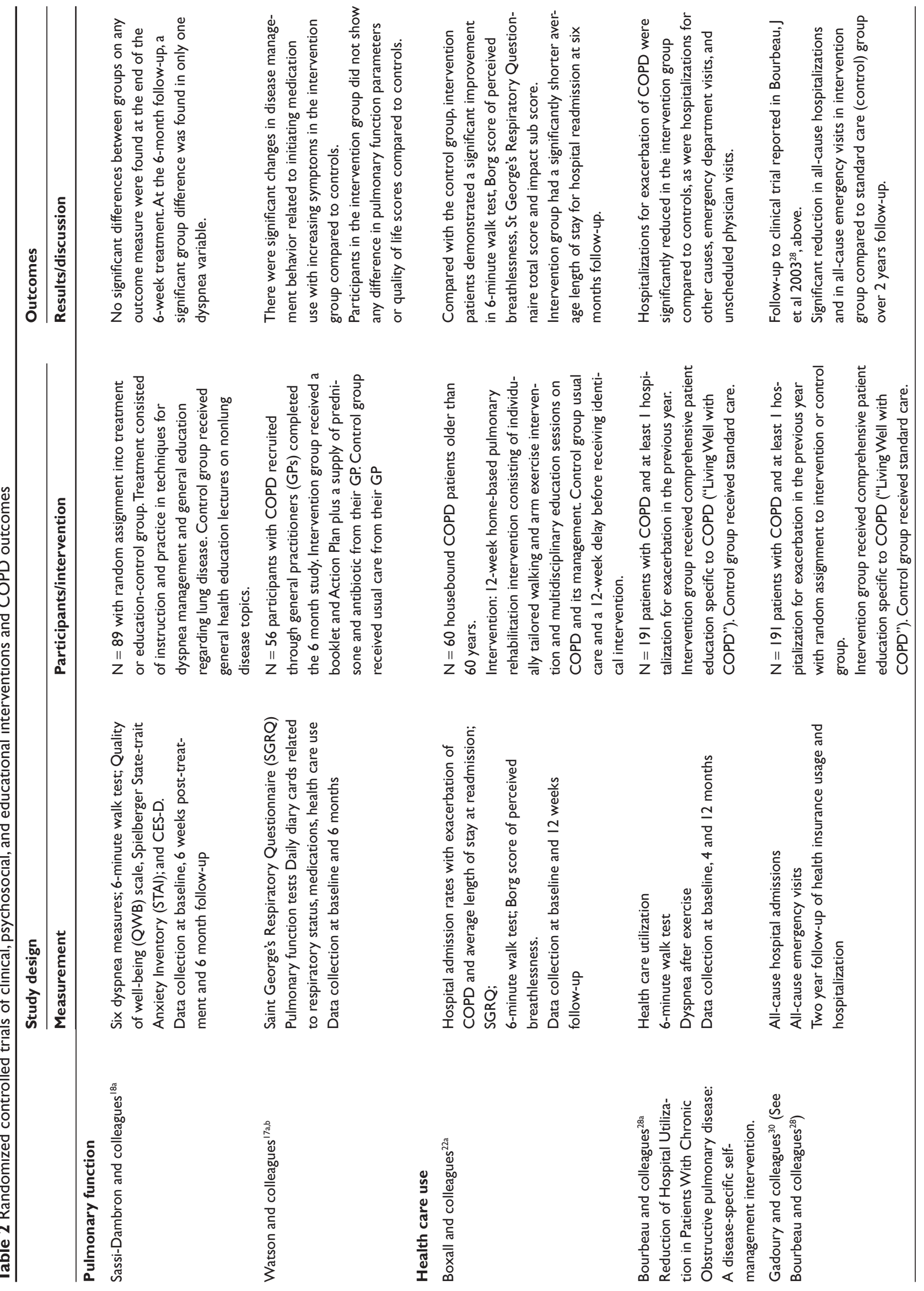



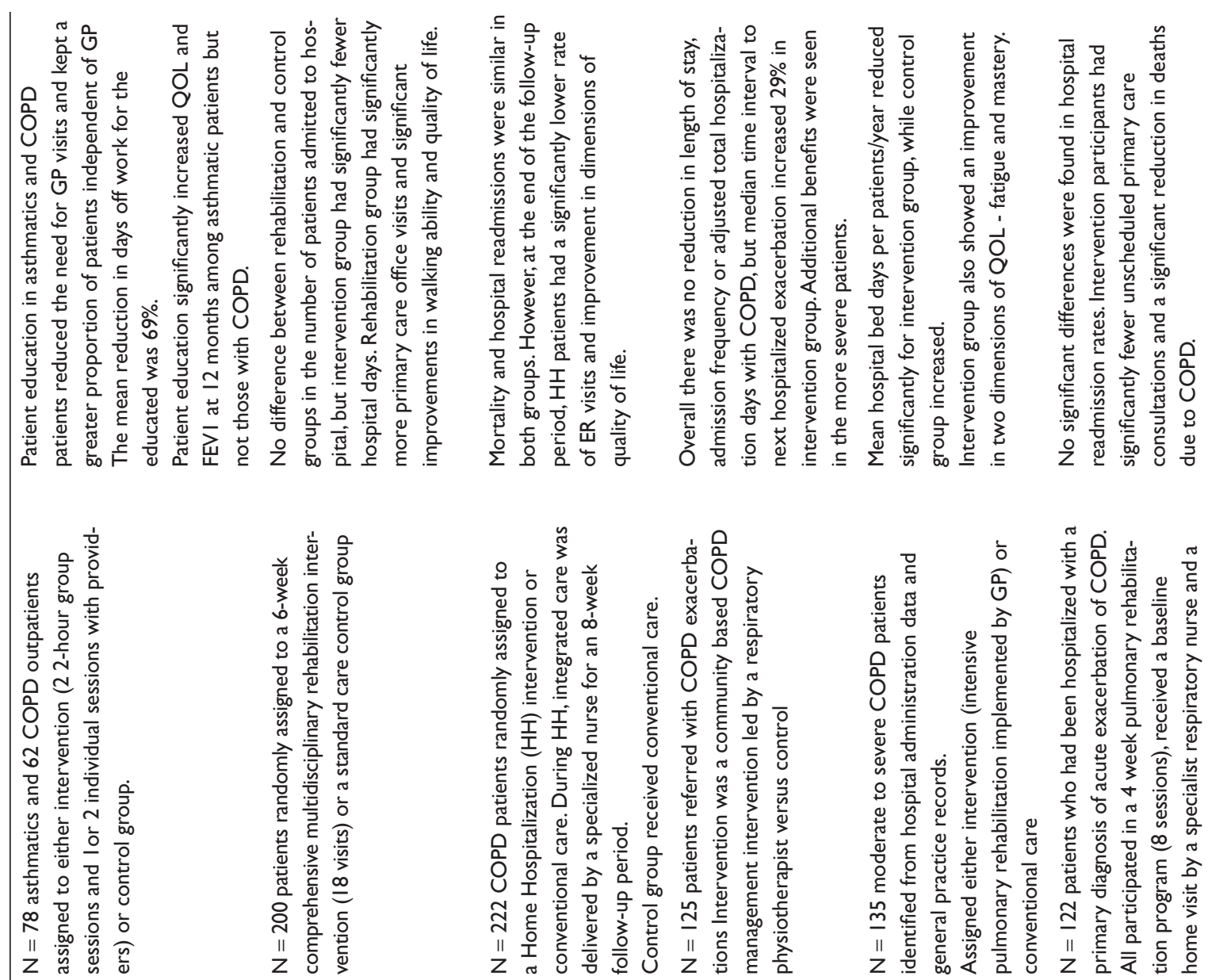

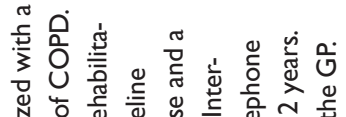
券

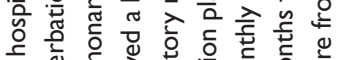

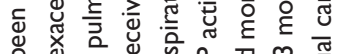

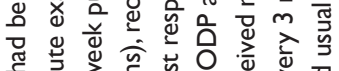

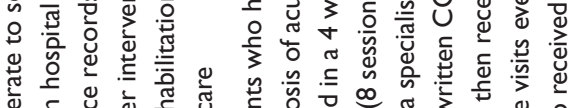

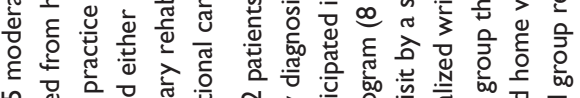

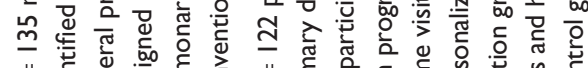
Z

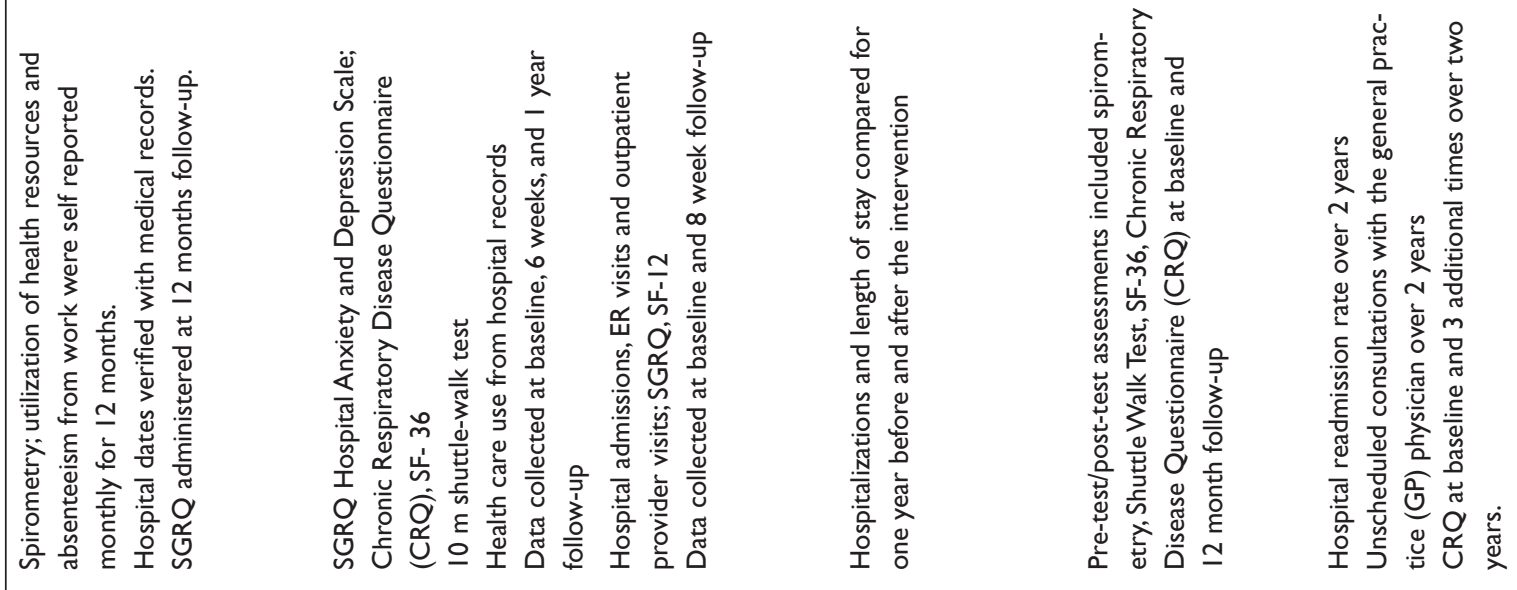
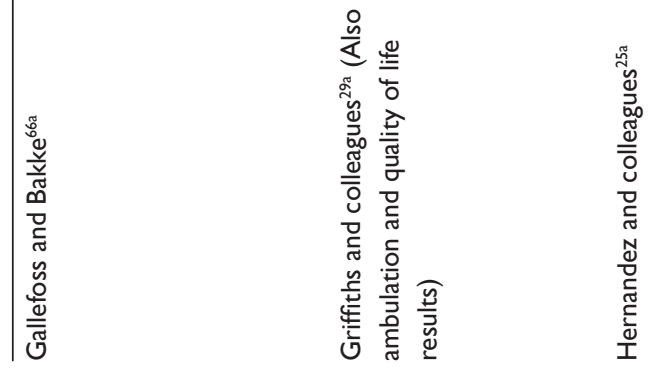

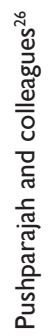

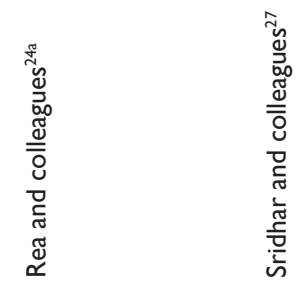

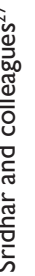




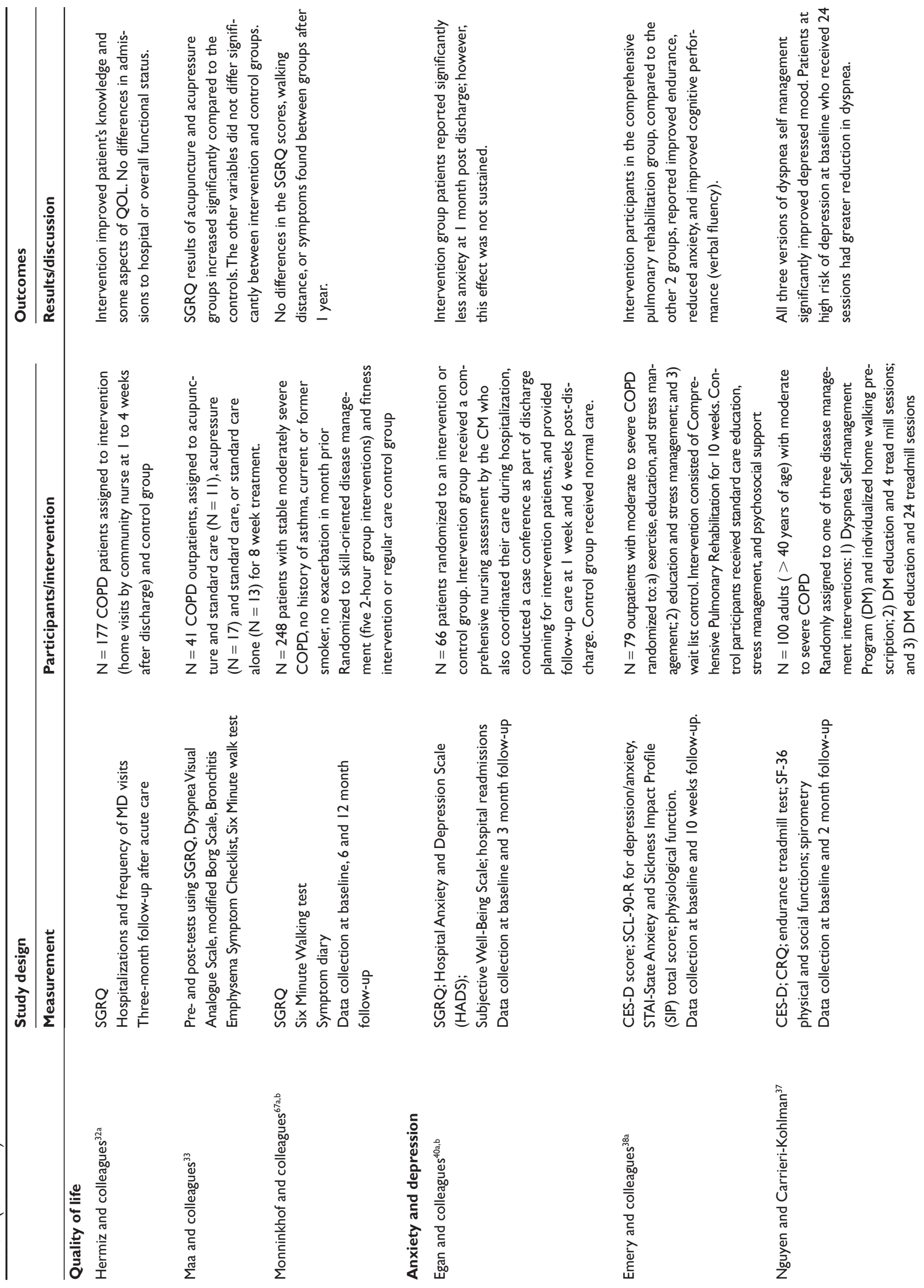



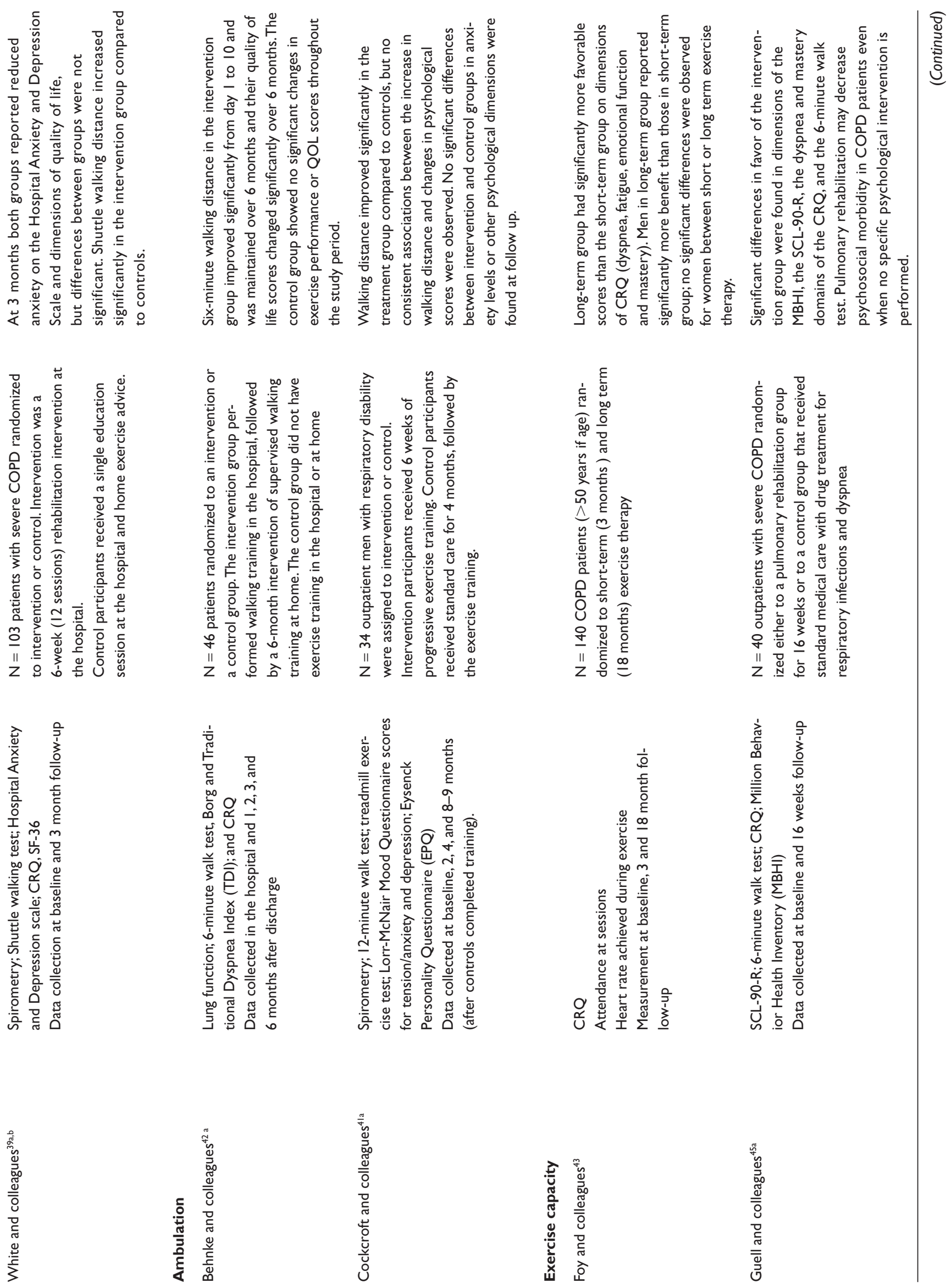


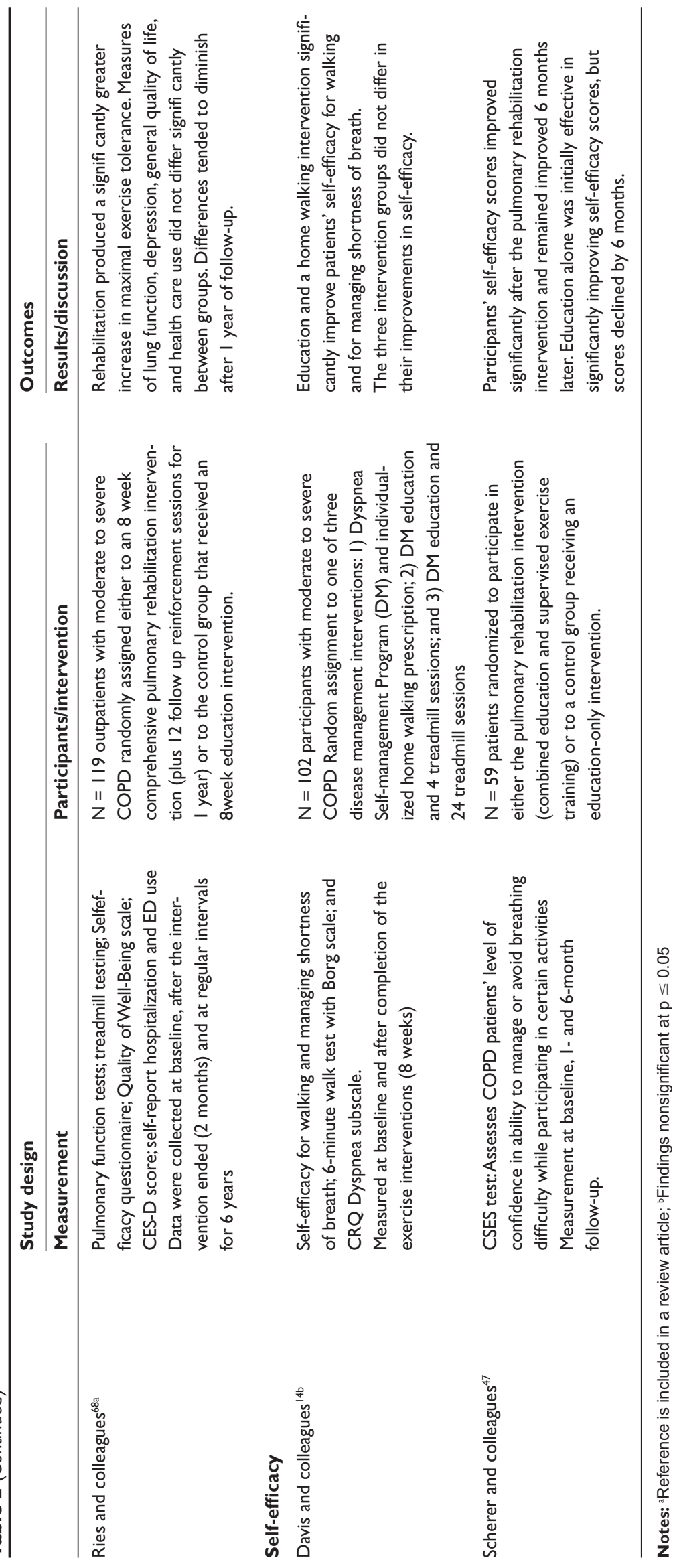


cost can also be raised. Several interventions have been comprehensive and intensive in terms of provider and patient time and effort and at least one ${ }^{27}$ has demonstrated significant cost effectiveness. In general, however, it is not clear how results as produced by more costly interventions stand up against less expensive means of intervention. What are the relative costs of various intervention modes for patients, for clinicians and for the health care system? In addition, questions regarding the capacity of interventions used to date to produce desired outcomes must be raised. How powerful in terms of theory and proven models are the interventions employed? This idea deserves further exploration. As noted, there is consistent evidence that asthma interventions aimed at improving patients' skills of disease management produce symptom and health care use improvements. ${ }^{48}$ How has work in the two areas, COPD and asthma, moved forward regarding theoretical approaches and intervention models?

\section{Improving patient management of COPD}

Both reviews and individual studies available in COPD suggest that one of the most studied modes among the range of interventions utilized, those designed to enhance COPD management by patients, can produce changes in health care use. This observation is made recognizing that evidence is not as strong as might be wished. The effect of interventions to enhance disease management by patients on other types of outcomes appears to be weak. Further, there is the odd paradox that although patients fear the need for health care, when need for services is reduced no accompanying improvement in quality of life outcomes has been observed. ${ }^{21}$ Nonetheless, such interventions may hold greater promise than currently evident for benefiting people with COPD.

As noted earlier, no one intervention can be expected to produce all the potential desirable results for people with the disease. However, in other conditions the evidence base has increased for interventions focused on developing patients' ability to manage disease on their own with guidance from their clinicians. Research has shown that such interventions have generally produced more than one outcome. ${ }^{27}$ Often one of these outcomes suggests a mechanism for the others. For example reduced health care use in asthma resulting from such interventions has usually been accompanied by reductions in symptoms. Often, but not always, enhanced quality of life $^{49}$ has been realized along with symptom reduction and/or less health care use. In addition more and more, results of interventions have been shown to benefit sub groups; in the case of asthma, those with more severe disease.
The lack of collective evidence for similar constellations of outcomes in COPD may be attributable to several factors. Perhaps, this is the case because COPD presents a more complicated clinical picture. The umbrella term COPD encompasses patients who might have the predominant pathology affecting their airways or the dominant pathology causing air sac destruction. Furthermore, co-morbidity or even poly-morbidity is so common in this condition that it is difficult to identify a homogenous group for study. The natural history and course of the disease may not allow for management by patients that can be adequately addressed in an intervention, that is, sufficient to result in fewer symptoms, less health care use and/or enhanced quality of life. Perhaps the methods and measures employed to assess outcomes in COPD are insufficiently robust to detect such changes. Another possible contributing factor may be that assessment of constituents of interventions has not been undertaken and is difficult to implement given current science base. Investigators of a single component intervention which might be thought to provide the clearest result regarding cause have produced benefits of such small magnitude that cause is, in fact, not easily attributed. This is in contrast to studies of multi-component interventions which show a greater magnitude of benefit but the casual element is not identifiable. However, COPD interventions to enhance patients' skills may not be as robust as they might be and may, as a group, comprise efforts insufficiently informed by findings in behavioral research in asthma and other chronic conditions. Collectively, they may not adequately reflect a focused approach or principals of learning and behavior change.

Over the past two decades, there has been increased interest in the asthma community in particular and chronic disease field in general in the psychosocial and behavioral factors associated with control of disease. ${ }^{50}$ This interest has led to introduction of theories and principles of behavioral science into asthma interventions. For example, one of the most explored has been social cognitive theory. This is a body of work evolved over many years beginning as social learning theory and most recently comprehensively articulated by Bandura. ${ }^{46}$ Social cognitive theoretical principles have infused studies in chronic disease generally ${ }^{51-53}$ and a model of self-regulation derived from the broader theory has been applied to asthma. ${ }^{54,55}$

Self-regulation is the means by which individuals learn and modify their behavior, eg, managing their COPD. The self-regulation model presented in Figure 1 (adapted from Clark and colleagues ${ }^{55}$ ) is based on the premise that a continuous and reciprocal interaction of factors external and internal to the individual produces behavior and 


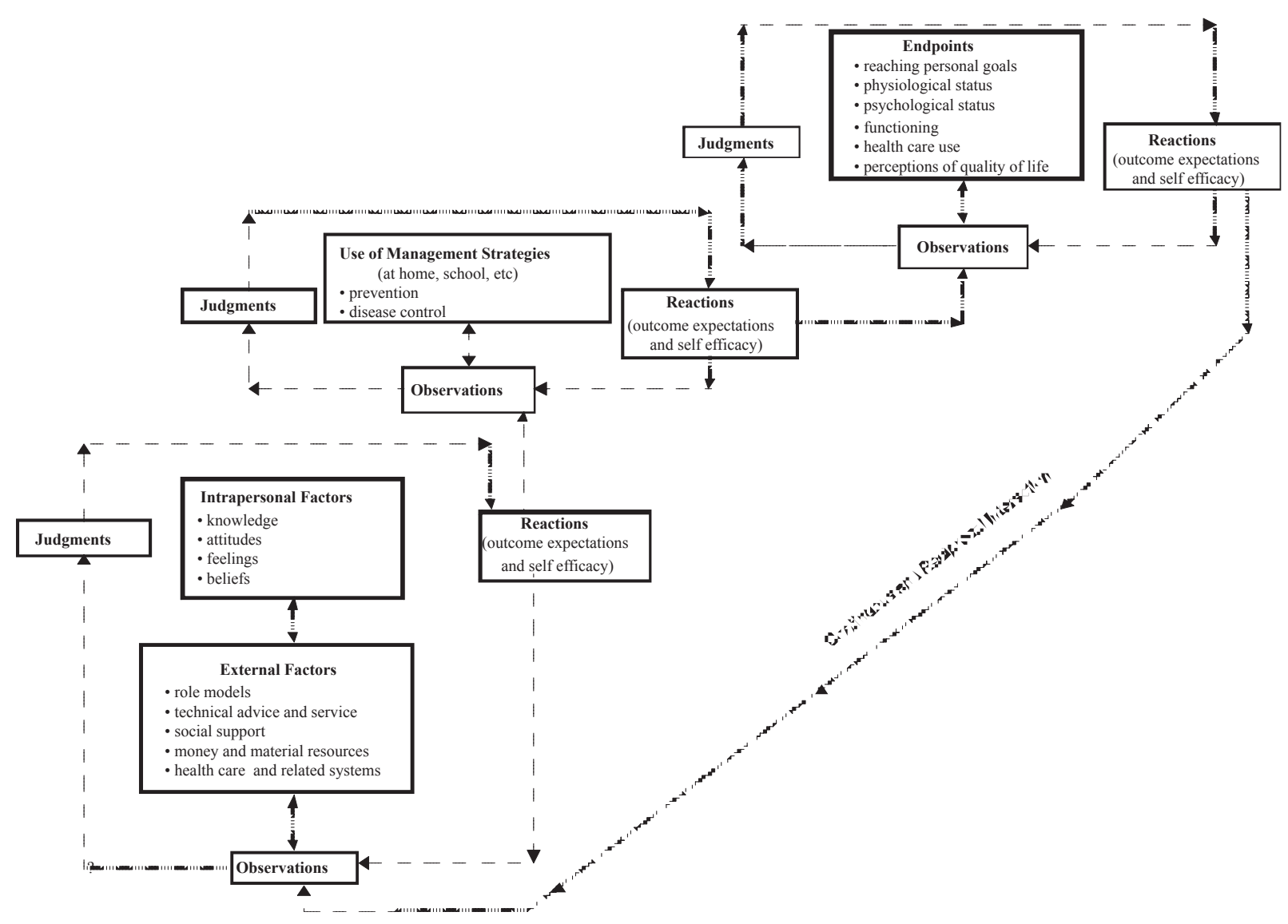

Figure I The continuous and reciprocal nature of self-regulation processes in asthma management.

outcomes associated with that behavior. These factors are identified, understood and modified using disease management strategies (including modification of the physical and social environments) to achieve a desired goal. This means his or her ability to observe himself and his social and physical environments, make informed judgments about the observations, try out new behavior and react appropriately (reactions being the belief that the behavior produced a desired result and the confidence to continue the behavior. The latter is referred to as self-efficacy). The model indicates that the most important feature of an intervention is its ability to enhance the self-regulatory process in the participant. As an example, in the case of individuals with moderate to severe COPD, episodes of shortness of breath/difficulty breathing are often a daily occurrence. To manage such episodes, the self-regulation model postulates that individuals observe key factors affecting their current management of the problem. Such factors might include, for example, feelings of fear or panic (intrapersonal factors), living alone (social factors), or difficulty breathing when performing routine housework (role factors). The effectiveness of current practices for managing episodes are observed and evaluated and new strategies developed for reaching a personal goal, for example, decreasing the occurrence of anxiety associated with breathlessness. In order to reach that goal, strategies might include, for example, using pursed lip breathing as soon as a shortness of breath episode begins. If using home oxygen therapy, one could manage anxiety associated with shortness of breath when performing housekeeping tasks by increasing the oxygen level when engaged in those tasks and/ or dividing the tasks into smaller steps and resting between each step. Alternatively, an individual might decide to identify a relative or friend to come in to assist with household tasks. New strategies are linked to the goal, in this case, less anxiety. Skills developed to create new strategies are skills of self-regulation. The model has been used in several successful asthma intervention studies ${ }^{56-58}$ and principles from the broader social cognitive theory in others. ${ }^{59-61} \mathrm{~A}$ focus on accepted behavioral science theories of learning and change has resulted in exemplars of robust asthma interventions that are reasonably reliable in producing constellations of desired outcomes. 


\section{Considerations for COPD}

It appears that compared to other conditions, eg, asthma, heart disease, and diabetes, there may be less information available in COPD regarding social and behavioral dimensions of management by patients and less use of relevant models to enhance their skills. How much can be extrapolated from these other conditions to COPD comprises a question. Compared to asthma, for example, patients with COPD may experience different or heightened emotional responses. Stigma and guilt may be more prominent in COPD and these patients may be more likely to sense an inevitable downward decline. Perhaps that most COPD patients are older and often more dependent on others attenuates their disease management efforts and the capacity of interventions to enhance them. As a result of these factors, the magnitude of benefits of a COPD intervention may never be as great as in asthma.

Nonetheless, extant studies suggest that the COPD community can make significant progress in developing effective interventions for patients, especially those designed to enhance their management skills, given the excellent work to date and drawing as relevant from the experience in other conditions. Such progress, in part, likely entails a reasonable level of consensus on the most desired outcomes for patients - probably a decision that is best made in collaboration with them. Enhanced quality of life and less health care use likely would be candidates for emphasis. Development and assessment of richer, theory-based interventions that are at the same time affordable and manageable within large health systems seem warranted. This direction for work requires availability of adequate research resources and tools allocated specifically for COPD. Such evaluation research could address a number of important questions including:

- Which social and behavioral science principles and models are most relevant for COPD interventions?

- Which interventions or elements of them are best matched to which patients?

- Can constellations of desired outcomes be realized from more robust interventions directed toward enhancing patient management skills including symptom and health care use reduction and enhanced quality of life?

- What are the specific elements or combination of elements that produce outcomes in interventions designed to help patients manage COPD more effectively ${ }^{62}$

- Can levels of depression and anxiety be reduced by more efficacious interventions or can more cost effective interventions be found?
Given the extent of current and anticipated levels of COPD in the world's population, more effective interventions that can generate strong, positive results deemed important to both patients and clinicians seem especially important to identify.

\section{Acknowledgments}

The authors wish to thank Wajeeha Shuttari and Megan Laver for their help with this manuscript. The authors report no conflicts of interest in this work.

\section{References}

1. ZuWallack R. How are you doing? What are you doing? Differing perspectives in the assessment of individuals with COPD. COPD. 2007;4:293-7

2. Dowson CA, Kuijer RG, Mulder RT. Anxiety and self-management behaviour in chronic obstructive pulmonary disease: what has been learned? Chronic Respir Dis. 2004;1:213-20.

3. Mikkelsen RL, Middelboe T, Pisinger C, et al. Anxiety and depression in patients with chronic obstructive pulmonary disease (COPD). A review. Nord J Psychiaty. 2004;58:65-70.

4. van Manen JG, Bindels PJ, Dekker FW, et al. Risk of depression in patients with chronic obstructive pulmonary disease and its determinants. Thorax. 2002;57:412-16.

5. Tashkin DP. The role of patient-centered outcomes in the course of chronic obstructive pulmonary disease: how long-term studies contribute to our understanding. Am J Med. 2006;119:63-72.

6. Rabe KF. Treating COPD - the TORCH trial, P values, and the dodo. N Engl J Med. 2007;356:851-4.

7. Prigatano GP, Wright EC, Levin D. Quality of life and its predictors in patients with mild hypoxemia and chronic obstructive pulmonary disease. Arch Intern Med. 1984;144:13-19.

8. Yohannes AM, Roomi J, Waters K, et al. Quality of life in elderly patients with COPD: measurement and predictive factors. Respir Med. 1998;92:1231-6

9. Hynninen MJ, Pallesen S, Nordhus IH. Factors affecting health status in COPD patients with co-morbid anxiety or depression. Int J Chron Obstruct Pulmon Dis. 2007;2:323-8.

10. Haughney J, Gruffydd-Jones K. Patient-centred outcomes in primary care management of COPD - what do recent clinical trial data tell us? Prim Care Respir J. 2004;13:185-97.

11. Clark NM, Houle CR, Partridge MR. Educational interventions to improve asthma outcomes in children. J Clin Outcomes Manag. 2007; 14:554-62.

12. Clark NM, Janz NK, Dodge JA, et al. Self-management of heart disease by older adults. Res Aging. 1997;19:362-82.

13. Roter DL. Hall JA, Merisca R, et al. Effectiveness of interventions to improve patient compliance: A meta-analysis. Med.Care. 1998;36:1138-61.

14. Davis AH, Carrieri-Kohlman V, Janson SL, et al. Effects of treatment on two types of self-efficacy in people with chronic obstructive pulmonary disease. J Pain Symptom Manage. 2006;32:60-70.

15. Devine EC, Pearcy J. Meta-analysis of the effects of psychoeducational care in adults with chronic obstructive pulmonary disease. Patient Educ Couns. 1996;29:167-78.

16. O'Brien K, Geddes W, Reid D, et al. Inspiratory muscle training compared with other rehabilitation interventions in chronic obstructive pulmonary disease: A systematic review update. J Cardiopulm Rehabil Prev. 2008;28:12-141.

17. Watson PB, Town GI, Holbrook N, et al. Evaluation of a selfmanagement plan for chronic obstructive pulmonary disease. Eur Respir J. 1997;10:1267-71. 
18. Sassi-Dambron DE, Eakin EG, Ries AL, et al. Treatment of dyspnea in COPD. A controlled clinical trial of dyspnea management strategies. Chest. 1995;107:724-9.

19. Adams SG, Smith PK, Allan PF, et al. Systematic review of the chronic care model in chronic obstructive pulmonary disease prevention and management. Arch Intern Med. 2007;167:551-61.

20. Bourbeau J, Collet JP, Schwartzman K, et al. Economic benefits of self-management education in COPD. Chest. 2006;130:1704-11.

21. Effing T, Monninkhof EM, van der Valk PD, et al. Self-management education for patients with chronic obstructive pulmonary disease. Cochrane Database Syst Rev. 2007;4:CD002990.

22. Boxall AM, Barclay L, Sayers A, et al. Managing chronic obstructive pulmonary disease in the community. A randomized controlled trial of home-based pulmonary rehabilitation for elderly housebound patients. J Cardiopulm Rehabil. 2005;25:378-85.

23. Gallefoss $F$. The effects of patient education in COPD in a 1-year followup randomised, controlled trial. Patient Educ Couns. 2004;52:259-66.

24. Rea H, McAuley S, Stewart A, et al. A chronic disease management programme can reduce days in hospital for patients with chronic obstructive pulmonary disease. Intern Med J. 2004;34:608-14.

25. Hernandez C. Home hospitalisation of exacerbated chronic obstructive pulmonary disease patients. Eur Respir J. 2003;21:58-67.

26. Pushparajah S, McClellan R, Henry A, et al. Use of a chronic disease management programme in COPD to reduce hospital admissions. Chronic Respir Dis. 2006;3:187-93.

27. Sridhar M, Taylor R, Dawson S, et al. A nurse led intermediate care package in patients who have been hospitalised with an acute exacerbation of chronic obstructive pulmonary disease. Thorax. 2008;63:194-200.

28. Bourbeau J, Julien M, Maltais F, et al. Reduction of hospital utilization in patients with chronic obstructive pulmonary disease: A disease-specific self-management intervention. Arch Intern Med. 2003;163:585-91.

29. Griffiths TL, Burr ML, Campbell IA, et al. Results at 1 year of outpatient multidisciplinary pulmonary rehabilitation: a randomized controlled trial. Lancet. 2000;355:362-8.

30. Gadoury MA, Schwartzman K, Rouleau M, et al. Self-management reduces both short- and long-term hospitalisation in COPD. Eur Respir J. 2005;26:853-7.

31. Niesink A, Trappenburg JC, de Weert-van Oene GH, et al. Systematic review of the effects of chronic disease management on quality-of-life in people with chronic obstructive pulmonary disease. Respir Med. 2007;101:2233-9.

32. Hermiz O, Comino E, Marks G, et al. Randomised controlled trial of home based care of patients with chronic obstructive pulmonary disease. BMJ. 2002;325:938.

33. Maa SH, Sun MF, Hsu KH, et al. Effect of acupuncture or acupressure on quality of life of patients with chronic obstructive asthma: a pilot study. J Altern Complement Med. 2003;9:659-70.

34. Brenes GA. Anxiety and chronic obstructive pulmonary disease: Prevalence, impact, and treatment. Psychosom Med. 2003;65:963-70.

35. Rose C, Wallace L, Dickson R, et al. The most effective psychologically-based treatments to reduce anxiety and panic in patients with chronic obstructive pulmonary disease (COPD): a systematic review. Patient Educ Couns. 2002;47:311-18.

36. Coventry PA, Hind D. Comprehensive pulmonary rehabilitation for anxiety and depression in adults with chronic obstructive pulmonary disease: Systematic review and meta-analysis. J Psychosom Rev. 2005;63:551-65.

37. Nguyen HQ, Carrieri-Kohlman V. Dyspnea self-management in patients with chronic obstructive pulmonary disease: Moderating effects of depressed mood. Psychosomatics. 2007;46:402-10.

38. Emery CF, Schein RL, Hauck ER, et al. Psychological and cognitive outcomes of a randomized trial of exercise among patients with chronic obstructive pulmonary disease. Health Psychol. 1998;17:232-40.

39. White J, Rudkin, ST, Harrison ST, et al. Pulmonary rehabilitation compared with brief advice given for severe chronic obstructive pulmonary disease. J Cardiopulm Rehabil. 2002;22:338-44.
40. Egan E, Clavarino A, Burridge L, et al. A randomized control trial of nursing-based case management for patients with chronic obstructive pulmonary disease. Lippincotts Case Manag. 2002;7:170-9.

41. Cockcroft A, Berry G, Brown EB, et al. Psychological changes during a controlled trial of rehabilitation in chronic respiratory disability. Thorax. 1982;37:413-16.

42. Behnke M, Taube C, Kirsten D, et al. Home-based exercise is capable of preserving hospital-based improvements in severe chronic obstructive pulmonary disease. Respir Me. 2000;94:1184-91.

43. Foy CG, Rejeski WJ, Berry MJ, et al. Gender moderates the effects of exercise therapy on health-related quality of life among COPD patients. Chest. 2001;119:70-6.

44. Ries AL, Bauldoff GS, Carlin BW, et al. Pulmonary rehabilitation: Joint ACCP/AACVPR evidence-based clinical practice guidelines. Chest. 2007;131:4s-42s.

45. Guell R, Resqueti V, Sangenis M, et al. Impact of pulmonary rehabilitation on psychosocial morbidity in patients with severe COPD. Chest. 2006;129:899-904.

46. Bandura A. Psychological Modeling: Conflicting Theories. Aldine Transaction, New Brunswick, NJ. 2006.

47. Scherer YK, Schmieder LE, Shimmel S. The effects of education alone and in combination with pulmonary rehabilitation on self-efficacy in patients with COPD. Rehabil Nurs. 1998;23:71-7.

48. National Asthma Education and Prevention Program. Expert panel report 3: Guidelines for the diagnosis and management of asthma. National Heart, Lung and Blood Institute; 2007 August 28. Report No.: 3.

49. Janz NK, Mujahid M, Chung LK, et al. Symptom experience and quality of life of women following breast cancer treatment. $J$ Womens Health (Larchmt). 2007;16:1348-61.

50. Bachrach CA, Abeles RP. Social science and health research: Growth at the national institutes of health. Am J Public Health. 2004;94:22-8.

51. FisherEB, Brownson CA, O'Toole ML, et al. Ecological approaches to selfmanagement: the case of diabetes. Am J Public Health. 2005;95:1523-35.

52. Lorig KR, Ritter P, Stewart AL, et al. Chronic disease self-management program: 2-year health status and health care utilization outcomes. Med Care. 2001;39:1217-23.

53. Clark NM, Janz NK, Dodge JA, et al. Heart disease management by women: does intervention format matter? Health Educ Behav. 2007; Dec 15 [Epub ahead of print]

54. Clark NM, Zimmerman BJ. A social cognitive view of self-regulated learning about health. Health Educ Res. 1990;5:371-9.

55. Clark NM, Gong M, Kaciroti N. A model of self-regulation for control of chronic disease. Health Educ Behav. 2001;28:769-82.

56. Clark NM, Gong M, Wang SJ, et al. A randomized trial of a self-regulation intervention for women with asthma. Chest. 2007a;132:88-97.

57. Clark NM, Dodge JA, Roberts RH, et al. Congruence of parent and preteen reports of the preteen's experience with asthma. Poster presented at the American Thoracic Society International Conference in San Diego, CA, May 20-25, 2005.

58. Clark NM, Brown R, Joseph CL, et al. Effects of a comprehensive school-based asthma program on symptoms, parent management, grades, and absenteeism. Chest. 2004;125:1674-79.

59. Wilson SR, Scamagas P, German DF, et al. A controlled trial of two forms of self-management education for adults with asthma. Am J Med. 1993;94:564-76.

60. van der Palen J, Klein JJ, Zielhuis GA, et al. Behavioural effect of self-treatment guidelines in a self-management program for adults with asthma. Patient Educ Couns. 2001;43:161-9.

61. McGhan SL, Wong E, Jhangri GS, et al. Evaluation of an education program for elementary school children with asthma. J Asthma. 2003;40:523-33.

62. Peytremann-Bridevaux I, Staeger P, Bridevaux PO, et al. Effectiveness of chronic obstructive pulmonary disease-management programs: Systematic review and meta-analysis. Am J Med. 2008;121:433-443.e4.

63. Crowe J, Reid WD, Geddes EL, et al. Inspiratory muscle training compared with other rehabilitation interventions in adults with chronic obstructive pulmonary disease: a systematic literature review and metaanalysis. COPD. 2005;2:319-29. 
64. Bourbeau J. Disease-specific self-management programs in patients with advanced chronic obstructive pulmonary disease: A comprehensive and critical evaluation. Dis Manage Health Outcomes. 2003;11:311-19.

65. Ofman, JJ, Badamgarav E, Henning MJ, et al. Does disease management improve clinical and economic outcomes in patients with chronic diseases? A systematic review. Am J Med. 2004;117:182-92.

66. Gallefoss F, Bakke PS. Impact of patient education and selfmanagement on morbidity in asthmatics and patients with chronic obstructive pulmonary disease. Respir Med. 2000;94:279-87.
67. Monninkhof E, Van der Valk P, Van der Palen J, et al. Effects of a comprehensive self-management programme in patients with chronic obstructive pulmonary disease. Eur Respir J. 2003;22:815-20.

68. Ries AL, Kaplan RM, Limberg ML, et al. Effects of pulmonary rehabilitation on physiologic and psychosocial in patients with chronic obstructive pulmonary disease. Ann Intern Med. 1995;11:823-32. 
